\title{
The Deformation and Regression of the Concept of Efficiency of Lawsuit in Criminal Justice of Minors
}

\author{
Lei Xiaozheng \\ College of Criminal Law Science \\ Beijing Normal University \\ Beijing, China \\ leixiaozheng@163.com
}

\author{
Zhou Jie \\ College of Criminal Law Science \\ Beijing Normal University \\ Beijing, China \\ 18330117193@163.com
}

\begin{abstract}
For a long time, the applicability for juvenile criminal suspects or defendants in custody, whether to prosecute, and be sentenced to imprisonment, many case-handling organ lack for effective risk assessment, specification, which also does not have a serious, meticulous education and referral. The article is based on the empirical analysis and data research, advocates in the juvenile criminal justice, from starting point of the essence of lawsuit efficiency, litigation efficiency concept against blind "the handling: speed", "the handling convenience", emphasizes the procedure and the traditional habits, psychological science, such as positive fusion, help involved crime minors return to society smoothly.
\end{abstract}

Keywords-Lawsuit Efficiency; Juvenile; Litigation Culture; Judicial Resources; Legal Education

\section{INTRODUCTION}

The survival and development of minors and the national of a country, upright, civilization and so on are all closely related. This for China's social management innovation, control the social risk, has special historical and realistic significance. Rate of custody in juvenile criminal case processing, high rate, prosecuting, bail rate, not to prosecute rate is low, the rate of short-term freedom penalty decision is too high, these phenomena bring a series of problems: Many of the juvenile criminal suspects or defendants live, work and psychological severely affected; Many of the high cost of judicial resources or been needlessly cost; Detention facility burden, custody of the cross "infected" problems; The relation between an offender and the victim has not been timely repair; To illegal crime rates are high, difficult to return to society and other issues are also increasingly prominent. Nowadays, many minors criminal personality not only failed to be fundamental correction, but breed antagonism of the judicial system, the social risk also will increase. One of the crucial reasons is the deformation of the lawsuit efficiency. So to speak, ignore the minor criminal suspects and defendants comprehensive correction and return to society, to "efficient" proceedings, may be just the appearance of justice.

\section{THE RISE AND DEVELOPMENT OF THE CONCEPT OF EFFICIENCY OF LAWSUIT}

In the rise and development of the concept of efficiency of lawsuit and the traditional judicial process "non-economic" are closely related. Since modern times, in the popular concept of a power struggle and dependent on the context of the justice of due process of law, "litigation explosion" and "litigation delay" often associated. Increasingly complexities of justified legal procedures face, from time to time, cost and income imbalance: due process is proud of its fine judiciary, which, however, brings the huge cost of human resources and expenses, in a nutshell, it costs both "money" and "time". According to Posner, representative of legal economics, the second meaning of justice is efficiency, in the world of scarce resources, the pursuit of efficiency is the greatest justice: "the law itself - its rules, procedures and system, is greatly focused on promoting economic benefit". Facing the lengthy justice, more and more people argue that judge judicial quality must consider three factors: One is the litigation cost, the other is to settle the time required, it is to find the real and the degree of the applicable law correctly [1]. As a result, the lawsuit efficiency emerging concept, is mainly refers to in the course of legal proceedings, subject to faster, with fewer resources to effectively solve more disputes [2]. Litigation efficiency is to describe the speed of its process and the number of dispute resolution, as well as in the process of litigation how people use and save various resources. Among them, the litigation costs means how much the procedure main body (including the state organs, the parties, and other players) in the process of litigation, consumes resources such as the sum of judicial resources. Litigation efficiency means achieving the lowest costs, with fewer resources and the least amount of time spent to resolve the dispute. Waste of time or delay of the legal period often means that the efficiency of procedure main body of lawsuit in unit time is reduced, and at the same time result in an increase in resources cost. Objective is concerned, countries on the basis of the efficiency of lawsuit in the judicial reform, the main line is as fast as possible to solve disputes, resolve disputes, save and make full use of all kinds of litigation resources as much as possible. In the judicial reform in our country, on the basis of the justice and 
efficiency value target, the efficiency of lawsuit is generally compared with litigation justice.

\section{THE DEFORMATION IN THE CRIMINAL JUSTICE OF MINORS}

The criminal procedure law amendment (2012)in title 5 chapter 1 specifically for minors to make special provision proceedings, criminal case involved the guideline and principle of minor crime litigation procedure, right protection, legal aid, social investigation, compulsory measures applicable, appropriate adult system, attach conditions not to prosecute, public trial and criminal record storage, etc. The system from the normative external form, no substantial gap with the United Nations criminal judicial criteria. However, from that of their judicial operation, China's human rights protection of juvenile criminal justice is still staggering in its competence. For example, high, high rate of prosecution, high rate of custody in jail sentence and other issues still exist. There are still many institutional constraints. The reasons are multifaceted. One of the important aspects is the deformation of the concept of the efficiency of lawsuit.

\section{A. The Efficiency of Lawsuit and the Handling Speed, Convenient "Case"}

Define abbreviations and acronyms the first time they are in the juvenile criminal justice, in order to realize the special protection of juveniles litigation rights, carry out a series of procedural rights in the United Nations criminal judicial criteria special protection principle, is unable to avoid a real problem is that, according to the existing judicial cost, configure scientifically and effectively judicial resources? To this, there is a lot of controversy. View of the theory of "low efficiency", carry out and implement these basic principle means that directly improve the litigation cost, decrease the efficiency of lawsuit, and the existing judicial resources configuration in many conflicts, should avoid the implementation of some of the "waste" or "fancy" reform; In some local public security and judicial organs, the understanding of the efficiency of lawsuit mainly include "fast, fast", "province," and pare to optimality of "make full use of these factors. Just focus on the "good" as a result, litigation, litigation efficiency focus on "fast".

In minor criminal cases, we believe that this kind of idea for juvenile justice has a certain practical value. Based on the tolerance of sex in the criminal law, legislators to use less with minimum expenses - even without penalty with other penalty alternative measures (it), and obtain the largest social benefits, effectively prevent and control crime [3]. Based on this, the social harmfulness is not big, subjective vicious smaller underage criminal suspect or defendant, but don't see v. v. v., but slow is slow to, try to expand the use of simple procedure, criminal reconciliation, to promote the case to end as soon as possible, make its return to society smoothly, it is quite necessary. However, the reality is often much more complex The lawsuit efficiency in practice of ideas could possibly be alienated to the handling speed, convenient "case". We see that in many places of the juvenile criminal cases, regardless of weight, fast detection, fast acquisition, fast sentenced to accompany a bet on issues such as quite outstanding. For a long time, the applicability for juvenile criminal suspects or defendants in custody, whether to prosecute, is sentenced to imprisonment, many case-handling organ for effective risk assessment, specification, also does not have a serious, meticulous education and referral. Some case-handling organs adhering to the "working speed" and "handling convenience" point of view, the one-sided pursuit caseload. Some investigators resist the use of conditional not to prosecute. They believe that treatments and education will greatly increase the workload, increase the risk handling the case.

\section{B. The Overlook of the Defendants Comprehensive Correction and Return to Society}

More prominent problem in performance, in many rural areas, even if the underage criminal suspect or defendant was not in custody, not to prosecute non-durance penalty mitigation measures, such as, they still faced a series of problems: return to society More prominent problem in performance, in many rural areas, even if the underage criminal suspect or defendant was not in custody, not to prosecute non-durance penalty mitigation measures, such as, they still faced a series of problems: return to society Subject to the government to buy services, social work system in unbalanced development and the overall factors, such as many underage criminal suspect or defendant failed to get effective regulation and education, especially to help remove antisocial behavior and psychology, and then return to the crime. The warning to minors' criminal justice is that ignoring the minor criminal suspects, defendants' comprehensive correction and return to society, to "efficient" proceedings, may be just the appearance of justice.

\section{The Possibility To The EFFICIENCY OF LAWSUIT}

Holding the quick buck mentality, is unable to effectively solve the problem of juvenile criminal justice Some scholars reflect China's reform and opening up 30 years "juvenile justice" research, thinks is basically a beyond the thoughts of research of social conditions, lack of empirical research and important original achievements: "It's just a from the splendid prosperity: Most mold the article structure, characteristics and countermeasures (reason), discusses the boring (family, school, society), and the conclusion is mostly correct nonsense, strengthen, improve, value) ". [4] How to guide and apply the concept of efficiency of lawsuit in Criminal justice of minors?

\section{A. The Institutional Regression of "Inefficient System"}

Never adults the history of legal system, for a long time, western countries tried "welfare model", "justice model", "restorative justice model", etc., the focus of its value balance basically is: How to protect minors' rights, and should take the social protection order, not the pursuit of pure "litigation efficiency". "Restorative justice model", in particular, it emphasized on the concrete results "repair justice, reshape the social harmony". To achieve the purpose of the reform of prisoners, and social return, it have to increase some necessary application Settings, such as strengthening the sin of minors and negotiation between the victim and the community and other stakeholders, emphasize to wade sin the special education of minors and treatments in seemingly "inefficient" system. Comprehensive theory of "efficiency" view, minors' 
pursuit of the value goal of criminal justice must not "get rich quick", seemingly trivial, complex procedure and supporting system, in an integrated education of minors, promote their return to society, for example, its essence promoting the comprehensive effect of the law.

\section{B. The Efficiency of the Lawsuit and Maximize Children's Benefits}

At present, more and more people realized that the traditional concept of litigation efficiency focus on the process of judicial value. In fact, the judicial process is not open around the result value. Moreover, achieve an organic unity of the two is the more profound understanding of efficiency value. Claims for this reason, many research results in the perspective of lawsuit benefit to understand and carry out "justice and efficiency". Specifically, "efficiency to describe the speed should be a lawsuit, the number of dispute resolution, as well as the people in the process of litigation on the degree of utilization degree and save resources, its emphasis is to quickly solve disputes, as much as possible and make full use of resources and save all kinds of litigation. The emphasis and benefit is the result of good." [5]

In the juvenile criminal justice, advocate the lawsuit efficiency which is not to against the efficiency of lawsuit, but in comply with the legal time limit, to promote the lawsuit efficiency under the premise of fully considering the tradition of" protection of children "in our country. The survey found that criminal records sealed system despite the "efficiency", but rather on benefits significantly: It is advantageous to the weakening of the juvenile delinquents crime tag psychology; their study, employment, better return to society; Reducing juvenile crime rates. According to the empirical juvenile criminal justice reform "a survey of project, such as Qingdao, Dezhou of Shandong, Taiyuan of Shanxi ,Wen 'an of Guizhou, Shanghai, Xiamen, 263 criminal records were sealed juvenile delinquents, a year later was not found to crime. Another example, in Shanghai, Beijing, Jiangsu province, Sichuan province, Procuratorial Organs with the measures of psychological test results evaluation of custody, decided not to indict risk. 1, based on the above-mentioned areas 103 involved crime minors has carried on the questionnaire survey, $68 \%$ said they would like to accept the psychological help and related skills training; After rectification, many involved in the crime minors become positive and optimistic life attitude. Since january1, 2010, the object accept correction in the region, is still not found someone to crime. In Beijing, Jiangsu,
Shanghai and other places, in the enterprise to establish some of the "love education of minors base", for those who are no fixed residence, no stable economic source, nothing in friends and family care for sin outside minors, accommodation during cases, to obtain a guarantor pending trial guarantees, regulatory care services in aspects of education, imparting labor skills, so they can enjoy according to law and local minor criminal suspects the right to apply for and obtain a guarantor pending trial [6]. These mechanisms, though there are some disputes, on the special protection, prevent to crime litigation rights has accumulated some practical effect than the more traditional.

\section{CONCLUSION}

The international covenant on civil and political rights stipulated in paragraph 4 of article 14, the juvenile cases, on the program should be given their age and need to help them. In grass-roots society, the "new man" it is difficult to "help" alone, more can't expect "capital". In the juvenile criminal justice, litigation efficiency concept against blind "the handling speed", "the handling convenience", emphasizes the procedure and the traditional habits, psychological science, such as positive fusion, help involved crime minors return to society smoothly. In the juvenile criminal justice, litigation efficiency concept against blind "the handling speed", "the handling convenience", emphasizes the procedure and the traditional habits, psychological science, such as positive fusion, helping involved crime minors return to society smoothly.

\section{REFERENCES}

[1] [U.S]Posner, the problem of jurisprudence, Translated by Su Li, Beijing: China University of Political Science and Law Press, 1994, p. 493.

[2] John Leubsdorf, The Myth of Civil Procedural Reform, in Civil Justice in Crisis, edited by Adrian A.S. Zuckerman , London: Oxford University Press, 1999, p. 55.

[3] Chen Guangzhong, "Research on the Problem of the Basic Theory of China's Judicial System”, Beijing: Economic Science Press, 2010, pp. 571- 538.

[4] Chen Xingliang, "the Value Structure of Criminal Law", Beijing: China University of Political Science and Law Press, 1998, p. 353.

[5] YaoJianlong, "From the Splendid Prosperity: Juvenile Crime Research 30 years", Beijing: Youth Research, 2009. (1).

[6] Tan Shigui, Huang Yongfeng, "Studies of the Efficiency of Lawsuit", Beijing: New Oriental, 2002. (1). 